\title{
A complex systems approach to constructing better models for managing financial markets and the economy
}

\author{
J. Doyne Farmer ${ }^{1}$, M. Gallegati ${ }^{2}$, C. Hommes ${ }^{3}$, A. Kirman ${ }^{4}$, P. Ormerod ${ }^{5}$, \\ S. Cincotti ${ }^{6}$, A. Sanchez ${ }^{7}$, and D. Helbing ${ }^{8}$ \\ 1 Santa Fe Institute, 1399 Hyde Park Road, Santa Fe, NM 87501, USA \\ 2 DiSES, Universit Politecnica delle Marche, Ancona, Italy \\ 3 CeNDEF, University of Amsterdam, The Netherlands \\ ${ }^{4}$ GREQAM, Aix Marseille Université, EHESS, France \\ 5 Volterra Partners, London and University of Durham, UK \\ ${ }^{6}$ DIME-DOGE.I, University of Genoa, Italy \\ 7 GISC, Universidad Carlos III de Madrid, Spain \\ 8 ETH, Zürich
}

Received 1 August 2012 / Received in final form 9 October 2012

Published online 5 December 2012

\begin{abstract}
We outline a vision for an ambitious program to understand the economy and financial markets as a complex evolving system of coupled networks of interacting agents. This is a completely different vision from that currently used in most economic models. This view implies new challenges and opportunities for policy and managing economic crises. The dynamics of such models inherently involve sudden and sometimes dramatic changes of state. Further, the tools and approaches we use emphasize the analysis of crises rather than of calm periods. In this they respond directly to the calls of Governors Bernanke and Trichet for new approaches to macroeconomic modelling.
\end{abstract}

\section{Visionary approach}

In November 2010, European Central Bank (ECB) then Governor Jean-Claude Trichet opened the ECBs flagship annual Central Banking Conference with a challenge to the scientific community to develop radically new approaches to understanding the economy:

When the crisis came, the serious limitations of existing economic and financial models immediately became apparent. Macro models failed to predict the crisis and seemed incapable of explaining what was happening to the economy in a convincing manner. As a policy-maker during the crisis, I found the available models of limited help. In fact, I would go further: in the face of the crisis, we felt abandoned by conventional tools.

... we need to develop complementary tools to improve the robustness of our overall framework. In this context, I would very much welcome inspiration from other disciplines: physics, engineering, psychology, biology. Bringing experts from these fields together with 
economists and central bankers is potentially very creative and valuable. Scientists have developed sophisticated tools for analysing complex dynamic systems in a rigorous way. These models have proved helpful in understanding many important but complex phenomena: epidemics, weather patterns, crowd psychology, magnetic fields.

An important component of the FuturICT proposal will be to deliver the complementary tools that Governor Trichet is calling for. The FuturICT project will exploit the rapidly expanding capacity of ICT to develop a system to continuously monitor and evaluate the social and economic states of European countries and their various components, and, what is of particular importance for this discussion, the real economy, the governmental sector, the banking and finance sector, by developing and managing a massive repository of high-quality data in all economic and financial areas; This will provide a platform for the development and application of data mining, process mining, computational and artificial intelligence and every other computer and complex science technique coupled with economic theory and econometric methods that can be devoted to identifying the emergence of social and economic risks, instabilities and crises; FuturICT will provide the framework and infrastructure to perform what-if analysis, scenario evaluations and computational experiments to inform decision makers and help develop innovative policy, market and regulation designs. This will involve pushing the envelope of what is technologically possible, using new information and computational capabilities to greatly expand the state of the art in the collection and modelling of data, at a hitherto unprecedented scale. Perhaps as important we shall investigate the impact that new information technologies, coupled with a natural tendency of market participants to "herd", has had on the evolution of financial market prices. As Governor Bernanke said:

"The brief market plunge was just an example of how complex and chaotic, in a formal sense, these systems have become ... What happened in the stock market is just a little example of how things can cascade, or how technology can interact with market panic" (Interview with Ben Bernanke, the IHT May 17th 2010).

The only way to make a major advance in economic modelling is to explore entirely new approaches rather than make incremental modifications to existing models. The economic models developed will be tightly integrated with the broader sociological modelling effort of FuturICT. Such an approach will take us away from the comfortable belief that the macroeconomy is well understood and that only occasional shocks perturb it. To quote Lord Turner, head of the U.K. financial services authority:

"But there is also a strong belief, which I share, that bad or rather over-simplistic and overconfident economics helped create the crisis. There was a dominant conventional wisdom that markets were always rational and self-equilibrating, that market completion by itself could ensure economic efficiency and stability, and that financial innovation and increased trading activity were therefore axiomatically beneficial'.

The purpose of our project is precisely to take up Lord Turner's challenge and to build models and perform analysis of the economy as a complex system prone to sudden and major changes of endogenous origin. Our analysis will also show that the blind faith that has been put on the capacity of markets to self-organise in a stable way is misplaced. Better approaches, such as those we suggest, can help understand intrinsic fragilities of the economic system and help to provide appropriate policy measures to mitigate them.

\subsection{Goals}

We intend to use new tools in information and communication technologies to implement an integrated complex systems approach for understanding financial markets 
and the economy. This includes the collection of new data, new methods of empirical analysis, and the development of new mathematical and computational tools. This effort will be guided by emerging new conceptual paradigms such as network theory, market ecology, behavioural economics and agent-based modelling, and empirically grounded by laboratory experiments and micro data. By combining these ideas into a practical simulation and forecasting tool our goal is to build the foundations of a new paradigm within economics.

\subsubsection{Modelling the economy as a complex evolving network}

The view of the economy as a complex system is at least as old as Adam Smith, who (though not in these words) described the economy and the social welfare that it creates, as an emergent process based on the self-organized behaviour of independently acting, self-motivated individuals. Specific examples of complex systems in social and economic contexts include traffic flows, large supply chains, financial markets, group dynamics and crowd behaviour. Examples of pioneering papers which view socioeconomic issues as complex systems are in $[5,10]$.

Complex systems, which predominate in modern socio-economic systems, raise a daunting set of problems requiring new and innovative approaches. These systems are made up of a large number of interacting individual elements, such as people, companies, countries, cars. They challenge conventional thinking. For example, they are dynamic rather than static. They are probabilistic and not deterministic. They appear to very difficult to predict and control, and are permeated by non-linear or network interactions amongst the component agents. The individual elements of a system are influenced directly by the behaviour of the system as a whole, and at the same time their interactions lead to the emergent behaviour at the aggregate level of the system. The 'common sense' connection between the size of an event and its consequences no longer holds. Small changes have the capacity to trigger large scale events [an early demonstration of this is [103].

Complex systems are characterised by critical points and regime shifts, an example being public opinion and pro- and anti-war views, attitudes towards smoking bans, and so on. From a policy perspective, these features can lead to serious malfunctioning of the system caused by cascades across the network of the system. Examples include epidemic spreading, the spreading of congestion, power blackouts and the collapse of the interbank market.

Extreme events in such systems are observed much more often than is suggested by the standard assumption in applied econometric work that data follow the Gaussian, or normal, distribution. The frequency and sizes of floods, earthquakes, wars, financial asset prices and even economic recessions are characterised by highly non-Gaussian outcomes [82].

Techniques used in the analysis of complex systems are quite different from those used in conventional economic theory, with its emphasis on optimisation. They include data mining, network analysis, systems dynamics, agent based modelling, non-linear dynamics, catastrophe theory and the theory of critical phenomena. Much of our emphasis in extending economic theory is on agent based modelling, given that the economy is made up of interacting individual agents (people, firms, regulators, governments), each with the capacity to act with purpose and intent, each of which is acting in the context of networks in which the fundamental behaviour of the agent is not fixed, but which evolves in response to the behaviour of others.

The network view. One of the biggest successes of the complex systems approach has been the development of techniques for studying systems in terms of network models. Economics provides a rich set of networks to consider, in which the 
nodes can be many things. Examples that have already received considerable attention include interbank lending [22,23,45,62-64], international trade [57,58], corporate ownership [15,17,101,102], and input-output relationships in production [31]. There remain many more relationships to be studied. Most importantly, these networks all interact with each other, and these interactions remain unexplored. The analysis of coupled networks is at the forefront of network theory [29,72].

The vision of the economy as a system of evolving coupled networks provides a completely different policy perspective. A key feature is that the behaviour of the economy at the aggregate level emerges from the interactions, both of the individuals within each network and of the networks themselves.

Traditional policy recommendations are based on the reactions of individual nodes (people, firms, institutions) to changes in policy. The network approach we propose opens up the possibility of identifying and targeting key nodes within the system, thereby potentially increasing the effectiveness of policy. It further makes it possible for policy makers to influence the way in which the structure of the network evolves. So, for example, the Basel agreements have focused upon controlling and improving the viability of individual institutions rather than on the ways in which they are connected and hence the viability and resilience of the system as a whole. A classic example of the failure of this approach was that of Dexia, a Belgian bank which had to be rescued by government intervention only 3 months after having passed the official stress tests without any problem. For example, a complex systems network analysis can yield insights into the systemic banks in the financial network, which must be preserved from falling. These latter considerations have only recently come to the fore. This point has been heavily emphasized by the Bank of England (see [52] and [53]), but despite the establishment of the European Systemic Risk board there has been little reaction in terms of macroeconomic modelling to this issue.

The growth and evolution of the economy is reflected in the growth and evolution of these networks. The fluctuations and changes in the networks during the business cycle potentially give a much finer grained view of state changes in the economy than a few aggregate numbers such as GDP and unemployment. So far this remains almost unexplored territory.

FuturICT will provide a platform with the raw data needed to construct these networks, and to develop the tools to visualize them and analyze their interactions, growth and dynamics. It will provide the capability to do this flexibly, focusing on a given set of issues and the networks that are relevant for those issues.

Understanding network structure. A key aspect of the project will be the use of ICT tools to obtain information both on the structure of relevant networks at a point in time, as well as to monitor how they evolve over time. The models which are built must incorporate the key features of the network topologies, and have behavioural rules of agents which allow the structure to evolve over time. In particular, what was thought of as the key feature of financial networks, their connectivity, has to be supplemented by other network characteristics, such as degree distribution and clustering, which may provide indications of fragility.

In other words, by examining the evolution of several key characteristics, we aim to understand the dynamics of the networks. How do the networks change in time and what causes such changes? In an economic system this inevitably requires an understanding of the agents who make the decisions that cause the networks to change, though again it has to be emphasized that these decisions are not taken in isolation and are linked to those of other actors in the system.

Agent-based models are the natural tool for simulating complex systems in social science. In comparison to econometric models or the DSGE models of mainstream economics, which are formulated in terms of aggregate quantities, agent-based modelling is done at a microscopic level. Agent-based models operate at the level of individuals, 
who can be householders, decision makers at firms, or government regulators. Agentbased models make use of computer power to represent as many different agents as are needed. They do not rely on complex mathematical derivations or closed form solutions. This makes it easy to implement nonlinear behaviour without restrictions on the degree of realism. Off course stylized agent-based models, where (partial) analytical results are available are a valuable and complementary tool that can yield important insights.

In recent years behavioural economists have made great strides in understanding how real people behave in economic contexts. Agent-based modelling works hand-inhand with behavioural economics, incorporating its insights to model the decisionmaking of agents, and using the power of the computer to simulate their behaviour in the complex interacting coupled networks discussed above, to keep track of their interactions through their consumption, production, budgets, borrowing, lending, flows of goods and services, investment, trading, etc.

\subsubsection{Data and ICT-tools}

The economy generates vast amounts of data that are currently not being gathered and recorded in an integrated manner, and which can provide much deeper insight into the workings of the economy than existing data sources. Most current data collection in economics is geared for econometric and DSGE models, which only require aggregate data such as GDP, unemployment, etc. Network modelling and agent-based modelling, in contrast, are best done with finer grained data, such as information about the choices of individual householders. Information about the heterogeneity of behaviour is essential. Agent-based models can potentially make use of many different types of information, as described below.

The data collection that we propose here is motivated by the complex systems picture of the world economy presented earlier. In order to construct the coupled networks that make up the economy, and in order to validate and calibrate agent-based models that quantitatively describe the interactions that take place within these networks, we must collect detailed data. It is beyond the scope of this position paper to present a comprehensive plan of what should be collected and how it should be collected, but we give some examples to give the reader a feeling for the philosophy and the scope of what we have in mind. It is perhaps in this area more than any other where ICT makes a crucial contribution.

The data that one would like to obtain in order to get a realistic picture of the economy includes trades in financial markets with identity information, international trade, firm transactions (invoices and receipts), credit networks, transactions by individual consumers, and electronic text from the internet and other sources. While some of these data are already collected in piecemeal form, much of it is never collected or recorded, and even when it is, it is often not available or easily usable by researchers.

A simple example is given by trading on the foreign exchange market. Whilst traders can potentially trade with thousands of other traders they, in fact, trade with very few others. Getting data for the structure of the clustering of trading would be very useful for understanding the evolution of prices on this market.

In another direction, one of the breakthroughs in economics in the last few decades is the advent of economic experiments. ICT technology potentially enables this to be done more efficiently, more comprehensively, and on much larger scales, either through use of the web or through use of technology that allows volunteers to be monitored in their daily life, or data on activity such as cell phone usage to be anonymously monitored. 
Ultimately the economy is about the transformation of physical materials into manufactured goods, and the organizing of human activity into services. On a longer timescale, data concerning products, technologies and firms should be recorded so that we can understand more directly how the economy transforms human activity into material goods, information and services. (Here we define "technology" in a very broad way, to include everything from electronics to new financial instruments to changes in the legal system).

Financial markets. There are hundreds of millions of trades a day in financial markets. In foreign exchange markets alone almost three trillion euro are traded every day, about 25 times the daily world GDP. From the point of view of economic theory it remains a mystery why there should be so much trading. Why are foreign exchange markets so active? How much of this is due to real economic activity, and how much is speculation? To what extent do speculators play a useful role in setting exchange rates, and to what extent do they act to destabilize them? As already mentioned mapping the networks of traders would contribute to our understanding of the functioning of these markets.

We believe that to get proper answers to these questions one has to collaborate with selected governments and exchanges to obtain such data for some of the major markets in Europe, to make it completely anonymous and make it available. This could lead to a break-through in understanding how markets really function and what drives instabilities.

Inter-firm transactions and international trade. There exist substantial data sets documenting international trade. However, these data are typically highly aggregated and contain inadequate detail about the firms doing the trading and the products being traded. They are also not well integrated with data on domestic trades. One would like a much more fine-grained and textured view, integrated together with other data that can put such data in perspective and illuminate the underlying interactions.

For example, to document real economic activity one would like a record of the invoices and receipts of companies. Each invoice and receipt is for a particular product or service. If one had a record of invoices and receipts, one would have a detailed record of economic activity, a record of what is made, where it is made, and who makes it, making it possible to track the inputs and outputs of economic production at a detailed level. Most importantly, such a record would chronicle the interactions between different goods, and between goods and services. For example a large part of the trade between the countries of the EU is made up of goods which at an aggregate level are the same. Germany, France and Italy export cars to each other. Only a much finer categorisation of these goods will lead to a satisfactory explanation of this trade. Such data may be collected directly or indirectly. For example when goods are imported or exported they are insured and the insurance policy records the nature of the goods and their value.

While it is beyond the scope of even this project to collect such data comprehensively, by working together with a selected group of the largest international firms, and with cooperation (and some pressure) from the governments of a few EU countries, one could begin collecting such data and, by so doing, illustrate its power for getting a more fundamental understanding of how the economy grows and why such growth fluctuates in time. This could also be put together with financial and banking transactions to better understand the linkages within the economy.

Credit networks. The recent crisis made it clear how essential credit is to the functioning of the entire economy. It also made it clear how poor our information is about credit - the Federal Reserve Bank of the United States, for example, did not have the ability to track U.S. credit markets during the crisis, even though they 
have regulatory authority over U.S. banks. This has triggered a big push by central banks around the world to have better capabilities for tracking credit markets, and is leading to the collection of new data sets. The U.S. Federal Reserve Bank now has, for example, a detailed record of the transactions of all the commercial banks in the US on a minute by minute basis. Similar data collection projects are underway by the Bank of England and the European Central Bank.

There are serious confidentiality problems with public access of these data sets. We believe, however, that by working in partnership with these banks to create data which has been made completely anonymous, it should be possible to make useful data about credit networks available to researchers.

Transactions by individual consumers. There are billions of consumer transactions everyday. These are increasingly being recorded in electronic form, which provides an enormous opportunity to understand consumer behaviour. Many retail firms analyze these in detail to better understand how to market their goods; this unfortunately is also an impediment because it means that these data sets have considerable proprietary value. While some analysis has been published in the marketing literature, a great deal remains to be done. We intend to develop collaborations with retail firms to develop the potential of these data.

Electronic text. One of the central lessons of economics is that expectations are important. Unfortunately, however, they are very difficult to measure. The current method for measuring expectations is through surveys, but this method is slow, expensive, time consuming, and unless done very carefully, statistically unreliable. Modern ICT technology presents us with a much more efficient alternative: The modern world abounds in electronic text flows. These include an enormous number of internet sites, news, social media such as twitter, and mobile phone texting. By gathering this data and developing better methods for text analysis we have the potential to measure expectations in real time. Such measurements could be extremely useful for economic modelling, for example to monitor sentiment and make use of this in agent-based models.

Individual expectations are influenced by beliefs and opinions of other individuals through social networks. This raises the issue of contagion and the pace of diffusion of expectations and beliefs through social networks, which needs to be taken into account in agent-based models.

\subsection{Opportunities}

At the outset we quoted Governor Trichet, who has issued a challenge to create new tools for understanding the economy. Such tools will be designed to answer the questions of most interest to policy makers. The agent-based complexity models that we are proposing will provide an alternative method for answering these questions, that will give a different perspective than current models. There are two standard approaches. Firstly there are econometric, or time series models which seek to find structure in the macroeconomic data for economies. Secondly, dynamic stochastic general equilibrium (DSGE) models, which are the benchmark of modern macroeconomics. These are based on the rational economic individual who is capable of understanding the evolution of the economy and acting accordingly.

We intend to base our models on a very different vision. Under our approach individuals may have varying information, depending on what is behaviorally plausible. Aggregate phenomena are generated by the interaction of such individuals, who influence each other and interact with each other. Such an approach requires intensive use of ICT both for simulating our models and for gathering the data against which to test them. To this end, an important goal of FuturICT is to build a "flight simulator" for 
policy makers that can be used to obtain experience in managing financial-economic crises. The simulator that will be built will use advanced ICT-tools collecting real data and having state of the art graphics, to make it easy to visualize what the simulator is doing and what the outcomes of the simulation and different policy measures are.

An additional and important by-product of our project will be the increased accessibility of the data that we gather. As it becomes available this will enable a much wider audience to develop a more comprehensive understanding of the nature and evolution of our socio-economic systems.

\subsection{Challenges}

The grand challenge for us here is to greatly expand the state of the art in economic analysis and forecasting by using agent-based complexity models, along with integration of real-time data and real-time simulation through advanced ICT tools, to enable policy makers to monitor the global economy and detect potential crises in an early stage and to develop tools to prevent them. Particular challenges that stand out are the following:

\subsubsection{Financial stability}

An important challenge for FuturICT is to explore the (in)stability and resilience of global financial markets focussing on issues of agent heterogeneity, network effects, spreading of information, market psychology, social learning, and expectations. At the same time, many instabilities in financial markets are driven by nonlinear instabilities that are inherently mechanical or that derive from market structure. (Good examples are nonlinear instabilities driven by derivatives ([25], [79], or leverage ([97], [44], $[25])$. We will use the complex systems network approach to understand the nonlinear feedbacks that exist in markets more comprehensively, explore their interactions with each other, and in particular to model their interactions with human decision making.

There are many questions to be addressed with this approach: What are the causes of extreme events and crises? What preventive measures should be taken? If a crisis does occur, how should it be managed from a complexity perspective? What is the role of financial innovation? How can institutional design and market regulation contribute to the stability and resilience of global financial markets? It is now widely believed that modern markets have become much more vulnerable to sudden changes as a result of the development of automatic trading algorithms. The latter, for example, often incorporate stop loss instructions to sell when a price descends to a certain level. If many algorithms have the same thresholds this can lead to a cascade of sales as in May 2010 on the NYSE. This interaction between modern technology and market dynamics will play an essential role in the way FuturICT models financial markets. A question that is now being treated in a rather pragmatic way is how to limit the impact of automatic trading algorithms on price dynamics. This project will make concrete proposals as to how to do this without disrupting basic market functions.

\subsubsection{Macrostability}

Macroeconomics and business cycles have been studied for a long time but what we are proposing is a new perspective. A macroeconomy is a complex system, and current 
economics lacks a satisfactory theory of the sort of fluctuations in economic activity that are empirically observed. The EU macroeconomy is a multi-scale complex system of interacting national economies, where problems of small countries (Greece, Ireland, Portugal) may contagiously spread and threaten macrostability of big countries (Germany, France, UK) and even the global EU and world economy.

Once we accept that the volatility of financial markets is liable to increase rapidly from time to time without any exogenous shock, then we need to examine proposals that are deliberately designed to mitigate volatility. A case in point is the "Tobin Tax" on financial transactions. The basic argument is extremely simple: Adding friction will hinder large amounts of short term trades for very small profits. The assumption here is that such trades are destabilising, but this has to be shown, and the experience with markets where this tax exists already is inconclusive. Some have argued that it will almost certainly decrease liquidity by reducing market making, and therefore increase volatility. The Taiwan Stock Market, for example, has a substantial Tobin $\operatorname{tax}$ ( 25 basis points) and is among the most volatile. Thus, although the tax is being widely proposed as a way to reduce volatility in markets, the results of implementing it are far from obvious. This is just the kind of question that we intend to address using agent-based complexity modelling.

The current crisis has shown once more the importance of the feedback between the macro economy and worldwide financial markets. The global economy is a multiscale complex system and a multi-disciplinary approach is necessary to study its functioning. In particular, interactions and feedbacks between financial markets and the macro economy need to be studied to understand crises and improve their early detection and to develop new complexity based economic policy.

\subsubsection{Expectations and learning in a complex economy}

Expectations feedback and adaptive behaviour through learning are key ingredients distinguishing socio-economic systems from complex systems in the natural sciences. In economics the "particles think": They learn from experience and adapt their behaviour accordingly. A socio-economic complex system is an expectations feedback system between individual learning and emerging aggregate behaviour. A fundamental question is: What is the relationship between heterogeneous individual learning at the micro level and the emerging aggregate macro behaviour which it co-creates? This fundamental question may be addressed with stylized agent-based models with few agent types, to get insights in the interactions of heterogeneous rules and their aggregate behaviour. But a daunting challenge is to address interaction through simulations incorporating thousands or millions of highly heterogeneous agents, which do not reduce to simulation of interacting populations of a few types of agents, using advanced ICT tools and programming levels.

An empirically grounded theory of heterogeneous individual expectations and social learning is needed as a foundation for a complexity research programme in economics. Empirical testing of such a theory, both at the micro and at the macro level - through laboratory, field and web experiments and in empirical financial-economic data - should yield key insights into which emerging patterns are most likely to occur in complex economic environments and how policy makers can manage expectations driven socio-economic complex systems.

\subsubsection{Inequality}

Where does inequality come from? The core model of modern economics, general equilibrium theory, does not enable us to say anything about the distribution of 
income. The issue of inequality cannot even be addressed in the standard representative agent model in macro. Is inequality a inherent feature of complex systems with heterogeneous agents? But inequality is not just a matter of the distributions of income and wealth. A major concern of policy makers about, say, outcomes in health care or education across hospitals and schools is that such outcomes are "unequal" or "inequitable" in the key sense that they differ at any point in time. This seems inevitable in any complex system of interacting agents, but it is often a major concern to voters and hence to politicians.

Inequality also has an important geographical (e.g. North-South) component, which poses an additional challenge. Simulations should include agents that live in heterogeneous environments.

Distributional properties have an important impact on aggregate economic outcomes; for instance, it is well-known that the effectiveness of tax-cut policies aimed at sustaining consumption demand depends on the income distribution of tax payers. Other distributional issues are probably still undervalued in economics, as for instance the distribution of debt among and within the different sectors of the economy: public, corporate and households.

Policy makers face the problem of predicting and controlling distribution in an economy. For example, what are the best strategies to achieve a more egalitarian society, given recent findings by British sociologists [104]? Agent-based models naturally take into account the distribution of economic variables at individual levels and therefore can be valuable tools for policy design. A particularly important question is that of intergenerational inequality. To what extent should we make changes now to protect future generations?

\subsubsection{Sustainability}

The problem of protecting both current and future generations is manifest when considering the supply of food, water and energy, and understanding how we can maintain a high standard of living for the whole world without depleting natural resources and destroying biodiversity. How do we avoid or at least mitigate these key social, economic and security-related problems? These extremely difficult problems require trans-disciplinary teams and play to the strengths of FuturICT.

At present the state of the art for understanding the dynamic aspects of sustainability is system dynamics modelling, as used in the original Club of Rome study, Limits to Growth. Such models have certainly been useful in providing an understanding of the relationships between key components of earth systems. FuturICT will expand considerably the analytical techniques which are applied to such systems, beyond that of ordinary differential equations. For example, network theory, complex systems theory, multi-agent simulations, multi-level models, experiments and participatory platforms. We also take into account explicitly spatial and network effects, as well as heterogeneity of agents and randomness. FuturICT will also use new methods of investigation such as the Living Earth Simulator, the Planetary Nervous System, the Global Participatory Platform and Interactive Exploratories.

Another important area is climate mitigation. What are the optimal strategies to deal with climate change itself and its consequences, and how much will they cost? Current climate mitigation models assume general equilibrium. Production decisions maximize the utility of a representative agent, a typical person who exemplifies the average worker and consumer. Such models assume full employment and assume that firms have no unused inventories - everything that is produced is consumed. Since by assumption industries operate at full capacity there is no need to stimulate demand. Such models count the costs of converting to new technologies without giving 
any weight to the economic stimulus that such conversions might generate, i.e. they do not allow for the possibility that developing new technologies might put people who are otherwise unemployed to work, and thus stimulate demand and make the economy operate at a higher capacity. Perhaps even more important, they typically make highly questionable assumptions about technological progress (as discussed in more detail in the next section). Such models have never been back-tested against historical data and their predictive accuracy is highly questionable.

Building on the other work outlined in the FuturICT project in developing an agent-based model of the world economy, we intend to develop an alternative type of climate mitigation model. By constructing the model at the level of individual agents we have far more historical data that can be used to calibrate the model. By making use of results from behavioral economics we do not need to assume that agents are rational - we can instead use decision rules that have been calibrated against the behavior of real people. By collecting and calibrating against an extensive database on technological change, as described in the next section, we will employ more realistic models of technological progress. Most importantly, we do not have to assume that the economy is in equilibrium. We will study the effects of stimulus for new technologies, modelling the consequences of putting more people to work and making progress in new technologies, e.g. possible revolutionary transformations to a green energy economy.

\subsubsection{Technological progess and economic growth}

At the same time that modern economic growth theory embraces technological progress as the agent of change underlying growth, it has traditionally dealt with it in a very simple way. In a typical economic growth theory a technology is a black box embodied by a very simple production function. In contrast, Arthur and others have argued that to understand the patterns of technological progress one needs to look inside the black box and carefully model its constituents and their interactions with each other $[8,11]$. Technologies are recursively built out of other technologies, and technological change happens in an evolutionary manner: Existing technologies are recombined and only occasionally are genuinely new technologies created. Indeed, it has been argued that most innovations result from the specific demands of producers for improvements in their production technology. Recent work $([12,80])$ models the way in which the components of a technology depend on each other, and shows that using simple models for technological improvement, the rate of technological change and its diffusion depend on the interconnectivity and separability of the technology.

In FuturICT we intend to gather detailed information about technologies so that we can empirically and theoretically study the interaction graphs of technologies. This could potentially allow us to construct a theory of technological change that would be completely different than present economic theories, and that could have substantial predictive power about the circumstances required for economic growth. Indeed, empirical analysis done along these lines already suggests the value of this approach $([57,58])$.

\section{State of the art}

\subsection{Traditional economics}

Most of current economic theory is based on the postulates of the agent who is rational in the following sense of the term. The agent gathers all available information which 
is relevant to a decision. The behavioural decision rule which is then used is that the agent makes the optimal decision, given the information and given his fixed tastes and preferences. The decisions of others only affect the agent indirectly via the effects of such decisions on the set of prices facing agents. Agents operate autonomously and are not influenced directly by the decisions of others with their tastes and preferences held fixed.

With this as the model of agent behaviour, the major challenge of economic theory from the time of Jevons and Walras in the 1870s was to discover the most general set of conditions under which an existence proof of general equilibrium could be established. In general equilibrium, supply and demand balance in all markets, and there are no unused resources, so it is efficient in that sense. Important contributions were made by, for example, von Neumann [81] and Arrow and Debreu [7]. The main challenge in the decades around 1950 was to prove existence in a world in which time existed, and the final results on this were obtained in by Radner [3]. Shortly afterwards, it was demonstrated that in general equilibrium no a priori constraints could be placed on the shape of market demand and supply functions $([37,94])$. Further, that there was no theoretical presumption that factors of production were paid their marginal products [21]. In short, general equilibrium contains no clear testable propositions which would enable it to be refuted empirically. A detailed critique is given, for example, by Kirman [67]; see also [42] for a discussion of the limits and strengths of equilibrium.

The essential problem which is paramount in the framework that we will develop is how is aggregate behaviour related to individual behaviour. In other words the problem is that of aggregation.

In macroeconomics this problem was circumvented by making the assumption that the aggregate behaved like a rational individual. The representative rational agent model which is based on this assumption has become the standard tool of analysis. Moreover, modern macro dynamic models assume rational expectations, that is they assume that all the agents correctly specify the stochastic process that governs the evolution of the economy. They then find equilibria which satisfy this hypothesis $([75,76]$, for example). As an empirical tool, the model of the economically rational agent has essentially been the intellectual basis of a great deal of both social and economic policy. Much of the latter is based on the principle that agents react individually and "rationally" to changes in incentives such as tax and benefit rates. Under the guise of dynamic stochastic general equilibrium (DSGE), in recent decades the rational agent has become the foundation of mainstream macroeconomic models as well $([20,105])$. A key development over the past forty years or so has been to incorporate imperfect information into this model of rationality. In particular, situations in which different agents have access to different amounts of information, so-called 'asymmetric information'. The pioneers in this field were Akerlof [2] and Stiglitz [96]. This relaxation of the assumption that agents have complete information undoubtedly extends the empirical relevance of the model of the economically rational agents. The model of economically rational agents operating with imperfect information is the intellectual basis of the 'market failure' approach to economic policy, and specifically to regulatory policy, in the past few decades. However, the model is still based on the assumptions a) that agents have fixed tastes and preferences and behave optimally, b) that agents operate autonomously and are not influenced directly in their behaviour by other agents, and c) that agents have rational expectations.

\subsection{Recent developments}

Bounded rationality. In the last decades the awareness of the limitations of the rational paradigm among economists has steadily increased. In fact, these limitations 
have been stressed already in the past by well known economists. For example, Pareto said that people spent some of their time making non-rational decisions and the rest of their time rationalising them. Keynes emphasized that "expectations matter" and stressed the importance of market psychology ("animal spirits"). Simon [93] forcefully argued that economic man is boundedly rational, unable to compute optimal decisions, but instead using satisficing rules of thumb. Tversky and Kahnemann [100] showed in laboratory experiments that individual decisions under uncertainty are much better described by heuristics, and that these may lead to systematic biases. Schumpeter and Hayek already had a complexity view of economics with competing strategies and evolutionary selection. But these ideas did not withstand the rational expectations revolution in macroeconomics in the 1970s and 1980s.

Adaptive learning. Modern macro economics has also been influenced by ideas from bounded rationality (see e.g. Sargent [91]) and studied macro fluctuations under adaptive learning, where agents use a statistical model and update the parameters based on observable quantities to form expectations about the future (an extensive overview is Evans and Honkapohja [39]). Sometimes adaptive learning converges to rational behaviour, but more often than not it does not do so or, if it does, only extremely slowly. The latter observation is important because it suggests that most of the time even if it were theoretically possible, people will not have come to have "rational expectations" and that therefore it is the situation where this assumption does not hold that must be analysed.

Behavioural economics is developing alternative models for non-rational behaviour (e.g. altruistic behaviour, reciprocity, tit-for-tat, etc.) and behavioural game theory focuses on strategic behaviour which is not fully rational in the standard sense (see e.g. [30]). Laboratory experiments with human subjects have become a standard tool to test behavioural models, since one of its founders, Vernon Smith received the Nobel Prize in Economics 2002 (together with Daniel Kahnemann for studying the role of psychology in economics); see [33] on the important role of laboratory, field and web experiments within FuturICT. The evidence that people do not obey the standard axioms of rationality does not mean that we should develop other axioms but rather base our models on behavioural rules which seem to be consistent with observed behaviour. Akerlof and Shiller [3] have recently stressed the importance of "animal spirits" and the urgent need for behavioral economic modelling; see also Colander et al. [35] for a general critique on the failure of economics in the light of the financial crisis.

Behavioural finance argues that some financial phenomena can be understood using models in which at least some agents are not fully rational (see e.g. Barberis and Thaler [14]). In particular, Kahnemann and Tversky [65] developed an empirically supported alternative model, prospect theory, for decisions under risk as an alternative to traditional expected utility. Prospect theory incorporates psychological effects into economic decision making, such as the fact that there is an asymmetry between perceived profits and losses: individuals are less willing to gamble with profits than with losses. The advantage of the sort of model we propose in FuturICT is that we do not have to assume that all individuals behave according to prospect theory, for example, but we can allow for more heterogeneous types of behaviour.

Agent-based models. In the standard efficient market model, the hypotheses of rationality and homogeneity are normally invoked, so that the agents' individual behaviour can be neglected and strategies have all to be equal. As an alternative, taking individual interactions into account, agent-based models of financial markets have been studied extensively, e.g. the artificial Santa Fe stock market in Arthur et al. [9] and LeBaron et al. [71] and the Genoa Artificial Stock Market (GASM) $[84,85]$; see the survey [70]. Simpler, stylized models with essentially the same 
results have been introduced e.g. in Kirman [66], Brock and Hommes [28] and Lux and Marchesi [78]; see the survey [59]. Many more ABMs in finance have been developed and these capture the above mentioned stylized facts nicely (see [77] for a recent survey).

ABMs have also been developed to describe macro economic fluctuations, e.g. in Delli Gatti et. al. [38]. In an ABM scenario, empirical macroeconomic regularities should be expressed in terms of statistical distributions, such as the distribution of firms according to their size or growth rate (Steindl [95]). Also, suitable modelling strategies should be adopted and these should be capable of combining a proper analysis of the behavioural characteristics of individual agents and the aggregate properties of social and economic structures (Sunder, 2005).

A recent and prominent example of a large-scale artificial economy has been developed within the EU-FP6 project Eurace. The model captures a rich scenario of interactions between real and financial variables. This points out the validity of Agent-based Computational Economics (ACE) as innovative methodology for the study of economics. Eurace is a large-scale agent-based model and simulator representing a fully integrated macroeconomy consisting of three economic spheres: the real sphere (consumption goods, investment goods, and labour markets), the financial sphere (credit and financial markets), and the public sector (Government and Central Bank). Following the agent-based approach, Eurace economic agents are characterized by bounded rationality and adaptive behavior as well as pairwise interactions in decentralized markets. The balance-sheet approach and the stock flow consistency checks has been followed as a key modelling paradigm in Eurace. The computational results show the real effects on the artificial economy of the dynamics of monetary aggregates, i.e., endogenous credit money supplied by commercial banks as loans to firms and fiat money created by the central bank by means of quantitative easing $[32,86]$. In particular, Eurace shows the emergence of endogenous business cycles which are mainly due to the interplay between the real economic activity and its financing through the credit market, thus shedding light on the relation between debt, leverage and main economic indicators [86]. Furthermore, Eurace shows that a quantity easing monetary policy coupled with a loose fiscal policy generally provide better macroeconomic performance in terms of real variables, despite higher price and wage inflation rates [32]. See also [36] for a recent discussion of agent-based macro model related to Eurace.

One of the standard misconceptions about large agent based models (ABM) is that they are difficult to calibrate to empirical data. However, the main purpose of $\mathrm{ABM}$, is rather to be able to reproduce qualitatively some of the salient features of the real economy. It is not to fit the data in the way that is the ambition of econometricians. For the latter, one can assume that one has a good understanding of the stochastic process followed by the economy, in which there are a number of relatively standard tools such as "bootstrapping" available.

One of the standard problems with large agent based models (ABM) is that they are difficult to calibrate to empirical data. For a number of economists the main purpose of $\mathrm{ABM}$ is to be able to qualitatively reproduce some of the salient features of the real economy.

When the stochastic process is imperfectly known or exhibits non-stationarity the econometric approach has to be modified and one can no longer think of a system converging to equilibrium, (see [34]).

One of the major challenges that FuturICT proposes to meet is to provide approaches that allow one to fit the data with ABM models even when the stochastic process is imperfectly known or exhibits non-stationarity and the system does not converge necessarily to an equilibrium; see e.g. the discussion of an $\mathrm{ABM}$ for the housing market in the Washington DC area in Sect. 3.6. 


\subsection{The fundamental limits of mainstream thinking}

We recognise that economics has made advances in recent decades, and that it is by no means a completely empty box. However, to quote again from Jean-Claude Trichet: "As a policy maker during the crisis, I found the available models of limited help. In fact, I would go further: in the face of the crisis, we felt abandoned by conventional tools".

A similar attitude towards the crisis in the autumn of 2008 was adopted by policy makers in the United States. Olivier Blanchard [20], chief economist at the IMF, had written in August of that year, only a few weeks before Lehman Brothers failed, that "For a long while after the explosion of macroeconomics in the 1970s, the field looked like a battlefield. Over time however, largely because facts do not go away, a largely shared vision both of fluctuations and of methodology has emerged The state of macro is good". The state of macro is good! In August 2008! He went on to say "DSGE models have become ubiquitous. Dozens of teams of researchers are involved in their construction. Nearly every central bank has one, or wants to have one".

Despite this convergence of academic opinion around DSGE models, in the crisis American policymakers paid no attention to them whatsoever. Instead, they looked at what happened in the 1930s and tried to avoid those mistakes. So, for example, they nationalised the main mortgage companies, effectively nationalised AIG, eliminated investment banks, forced mergers of giant retail banks and guaranteed money market funds.

It is therefore necessary to move beyond, and in many ways to break decisively, with the fundamentals of mainstream thinking (e.g. [55]). The rational agent hypothesis is still pervasive in economics, however it might be qualified by mainstream practitioners. But the conditions under which the existence of general equilibrium can be proved $([87])$ are so restrictive as to be completely divorced from any empirical picture of the real world. Human cognitive capacities are known to be bounded ([92]). In the face of NP-hard optimisation problems, even supercomputers are facing limits so that optimisation jobs cannot be performed in real time any more (so, for example, there are 32 pieces at the start of a chess game, but computers have only been able to solve all possible positions when there are just 6 pieces on the board, and the computational task scales super-exponentially with the addition of each extra piece).

Above all, it is the equilibrium paradigm and the representative agent approach which we are intending to replace. From a policy perspective, the efficient market hypothesis has been very important in practice. This hypothesis implies the equilibrium paradigm. Yet, for example, financial markets are systems of extremely many dynamically coupled variables, and it is not at all obvious theoretically that such a system will have a stationary solution ([73]). If a stationary solution exists, it is not clear that it is unique ([1]. Further, as is well known since the formulation of the Lotka-Volterra equations in the 1920s, in systems of non-linearly interacting variables, the existence of a stationary solution does not necessarily imply that it is stable.

In short, the equilibrium, efficient markets paradigm cannot explains phase transitions; it does not allow us to understand innovations which occur as a result of endogenous system dynamics; it does not permit us to study the effects of different time scales of response, when, for example, fast self-reinforcing effects and slow inhibitory effects may lead to pattern formation in space and time ([99]), and neglects friction, without which it is difficult to understand entropy and other path-dependent effects. To remedy some of the deficiencies of the standard equilibrium approach to economics and the social sciences in general, a number of the partners in FuturICT are already participating in a project (NESS) on non equilibrium social science (for details see http://www. nessnet.eu/). 
A common simplification in economic modelling is that of the representative agent. This is certainly a curious assumption to make in the light of the financial crisis, when much of the focus is on the differing behaviors of creditors and debtors. In the Euro area crisis at the time of writing (November 2011), for example, it makes no sense at all to speak of the 'representative agent', the German government has quite different behavioral rules and constraints from that of, say, the Greek and Italian administrations.

A fundamental problem with the simplifying assumption of the representative agent is that it cannot explain the basic existence of economic exchange. As Arrow pointed out ([6]): "if we did not have [agent] heterogeneity, we would have no trade". A similar point was made by Keynes in his 1936 magnum opus, The General Theory of Employment, Interest and Money, when he noted that if all agents had identical expectations, market prices would fluctuate between zero and infinity.

In modern social and economic systems, percolation phenomena are ubiquitous. In other words, ideas, market sentiments, technologies, viruses spread across networks. The actual spread of any individual example is not determined so much by the average node degree, but by very particular features of network structure (e.g. [83]). Moreover, both specialization and innovation imply the existence of heterogeneous agents, and the latter in particular cannot be understood using the concept of the representative agent $^{1}$.

\section{Innovative approach}

\subsection{Networks}

Networks provide a good starting point to visualize any complex system. The economy can be thought of as a set of overlapping and strongly interacting networks. Some of the key networks needed to understand the economy in these terms include:

- Production. A good or service is a node, the goods and services required to produce it are its incoming links, and the goods and services it helps produce are its outgoing links.

- Firms. Individual firms are nodes, their incoming links are firms they invoice, and their outgoing links are the firms they get receipts from. This is strongly overlapping with the production network described above, but focuses on institutions rather than goods. One can organize the production and firm networks based either on monetary flows or on the flow of physical goods.

- Ownership. This is an inherently bipartite graph, with two types of nodes. One type of nodes are owners, who can be individuals or firms, and the other type of nodes are assets, which can be firms, commodities, bonds, derivatives, etc.

- Trading. This is closely related to the ownership network and describes with which other holders owners trade assets.

- Credit. Banks are specialized firms that lend money to individuals and other firms. The credit network is a bipartite graph in which one type of nodes are banks, and the other type of nodes are the individuals and firms, including other banks, that they lend to. Since banks also own assets and hold them as collateral they play a prominent role in the ownership and trading networks as well.

- Individuals. Ultimately the economy is about individuals, who live in households, use their labour to produce or supply their labour to firms, and consume. These

\footnotetext{
${ }^{1}$ For a review of what equilibrium theories have accomplished, what they cannot accomplish, and what is needed to go beyond them, see also Farmer and Geanakoplos [41].
} 
individuals are connected to the networks above in a variety of different ways they produce and consume goods, work for firms, invest in firms, trade in stock markets (possibly through their pension plans), and receive credit from banks. While it may be intractable to visually represent all 500 million individuals in the European Union, this network is the vital conceptual component of any economic model - the very fact that it exists explains what is meant when we talk of an economy.

The networks delineated above are not comprehensive. One can refine these, e.g. by breaking assets down into different types, or looking at more specialized networks, such as the movement of workers between firms or the network of patent citations and their relationship to firms or physical goods.

There are flows of many different quantities along the links in the networks above. For the production network, for example, one can monitor the flow of money, physical goods, energy, pollutants such as $\mathrm{CO} 2$, or critical materials. This makes it easy to relate economic activity to physical activity and resource constraints - a perspective that is often missing from conventional economic analyses - and makes this approach particularly useful for studying sustainability.

Breaking down a system into a set of interacting networks is only the first step in a complex systems analysis, but it can nonetheless be very useful by providing a schematic view of what the key components of a system are and how they interact. For example, see the discussion of leverage in Section 3.4 or the discussion of technological growth in Section 1.3.6. The FuturICT program will gather the data required to construct all the networks sketched above and more, and will use this representation as a basic tool for understanding the economy and its instabilities. This will go far beyond the state of the art - few of these individual networks have been constructed in any detail, and their interactions have largely never been studied. This will be by far the most comprehensive view of the world economy ever constructed.

\subsection{Market ecology and its role in financial instability}

Real agents have cognitive and resource limitations that force them to specialize. They build up specialized knowledge based on past experience and make most decisions using rules of thumb, without going through the effort of deductively thinking each situation through from scratch. The diversity of behavior can be enormous. The ecological approach classifies different types of behavior, dividing agents into groups in order to simplify the study of their interactions and evolution $[9,40]$.

Under this view small deviations from market efficiency support an ecology of interacting financial traders. This ecology is supported by the interactions of the financial sector and the real economy: Basic economic functions, such as trading to get liquidity or offset risks, generate profit-making opportunities. These are exploited by highly specialized financial speculators, who play the role of predators in a financial ecology. The diversity of strategies employed is enormous, including fundamental value investors, technical traders, statistical arbitrage, high frequency trading, and many others.

As in biology, predators play a valuable role in regulating and maintaining balance. The introduction of new species can disrupt this balance, destabilizing an ecology and causing irreversible changes (such as the introduction of rabbits into Australia). Similarly, financial strategies are constantly evolving and new strategies may destabilize the market. For example, the introduction of new mortgage derivative products and the misunderstanding of these products is widely believed to have played a key role in triggering the current economic crisis. 
Agent-based modelling and the study of market ecology provide a natural fit. The agent-based models of LeBaron, for example, suggest that market instabilities are associated with decreases in the diversity of financial traders [69]. This is not surprising - if there is no diversity in markets, there is no one to take the opposite side of a position, which can give rise to extreme price movements. FuturICT will collect data to better study market ecologies, with the goal of developing early warning signals based on shifts in the profit relationships between strategies and shifts in market ecology.

\subsection{A complex financial market}

As an illustration, consider an example of a market, but this time for a financial asset, ([4]). This starts with an empirical phenomenon, the collapse of the price of asset backed securities early in the current crisis. The paper first presents a simple theoretical model to capture the essence of the phenomenon and then ran simulations of a more general dynamic model in which the agents act in the same way as in the theoretical model to see if the model evolves to the states predicted by the theory. The goal was to model the general mechanism whereby investors, as a rule, trade securities without giving due diligence to fundamental information that is, they do not check on the toxicity of the asset. The rationale motivating investors, is simply that it is profitable to adopt this rule, because other investors have already adopted it.

The market consists of agents, who, in the case of the sub-prime crisis, we can think of as the banks who were both the issuers and the investors in these Asset Backed Securities,(ABS). Each agent decides whether or not to follow a rule, which is to purchase an ABS, relying on signals from the rating agencies, without independently evaluating the fundamental value of underlying assets. If enough other participants do so, the agent becomes convinced, not irrationally, that the ABS is highly liquid and hence easy to trade.

The ABS is toxic, with a certain probability the underlying asset was incorrectly graded, (the original borrower has already defaulted or has a high probability of doing so). Agents are linked together with trading partners in a financial network. When an agent receives an offer to buy a new ABS, she considers whether or not to check on the underlying asset. Each agent now calculates the expected gain to him of checking given the rules chosen by the neighbours in his network and checks if the expected pay-off is higher than that obtained by not checking.

It is not difficult to find the equilibria of this simple market, in terms of whether agents are checking or not, and there are two, one of which is always an equilibrium, and the other which only appears above a certain critical value for the probability of default on the underlying asset. In the first equilibrium no banks check on the underlying assets whilst in the second all banks do so. To test the stochastic stability of the two equilibria simulations were run in which agents noisily learn (they use reinforcement learning), whether to check or not. What transpires from the simulations is that the system always converges to the no-checking equilibrium if the probability of default is low enough, but a small increase in that probability can lead the market to collapse into the equilibrium in which everyone checks. Thus a small change in one of the parameters of the model can lead to catastrophic consequences at the aggregate level.

Consider Figs. 1(a)-(c). In the first we see the probability of default on an ABS issued at a given time. For each date we see the percentage of loans with a given date of origin which default after each period. This is steadily rising in Fig. 1(a). In Fig. 1(b) we see the evolution of the prices of the ABS over time, which remains 


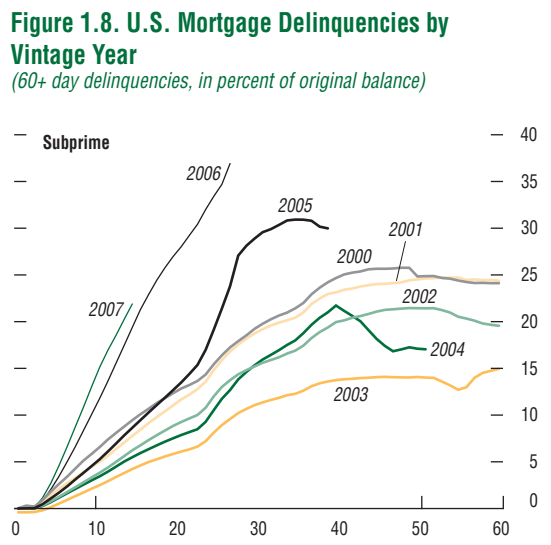

Figure 1.9. Prices of U.S. Mortgage-Related Securities
(In U.S. dollars)
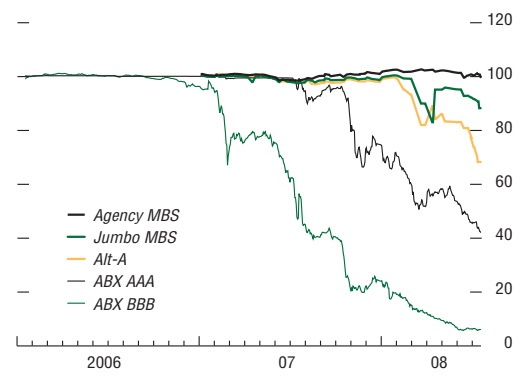

Sources: JPMorgan Chase \& Co.; and Lehman Brothers. Note: $A B X=$ an index of credit default swaps on mortgage-related
asset-backed security; MBS = mortgage-backed security.

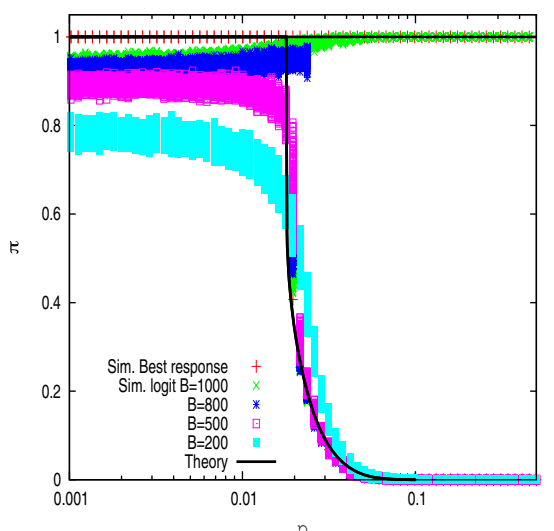

Fig. 1. Critical transition in an agent-based model of asset backed securities (ABS). Top panel: rising percentage of loans with a given date of origin which default; Middle panel: prices of ABS are stable, before suddenly collapsing; Bottom panel: critical transition from not checking to checking equilibrium.

stable and then suddenly collapses after a certain time. Finally in Fig. 1(c) where on the vertical axis is the proportion of agents not checking, the noisy best response process is shown collapsing to the checking equilibrium as the probability of default 
increases. If all agents were perfectly rational the process would not leave the nochecking equilibrium, but even a small amount of noise will cause the no checking equilibrium to suddenly shift to the one where everybody checks and the toxic assets are revealed to everyone and the prices collapse. Thus what was examined was the co-evolution of the default rates on mortgages and the prices of securities backed by those mortgages. The default rates steadily increased but this was not reflected in the price of assets until they suddenly collapsed and the interbank market froze. A continuous change at one level led to a discontinuous change at the aggregate level. Whilst one could establish the existence of the equilibria of the model analytically, it was necessary to resort to simulations to see to which equilibrium the learning process converged.

This underlines an important message. As soon as we are interested in real economic phenomena we cannot avoid examining how the economy behaves out of equilibrium and the characteristics of the states through which it passes, or to which it settles.

Another and very general example of cascading networks which are a source of systemic risk is given by [74].

\subsection{Expectations and learning}

In a complex system, individual agents lack the knowledge necessary to fully understand their environment and compute optimal decision rules. How do individual agents learn in such an environment and adapt their behaviour as the economy evolves and how does individual learning co-create aggregate behaviour? An important question is the extent to which agents are capable of learning better heuristics in complex non-equilibrium situations.

A theory of heterogeneous expectations for complex socio-economic systems has been proposed in Kirman [68] and Brock and Hommes [27]; see Hommes [61] for a recent survey. Agents act purposeful, choose between simple forecasting heuristics and tend to attach more weight to rules that have been more successful in the recent past. This theory of heterogeneous expectations has been successfully fitted to laboratory experiments with interacting human subjects [60].

A key finding is that in systems with negative expectations feedback, such as the classical supply driven hog cycle model, subjects are able to coordinate and learn the rational expectations equilibrium price, even when they have very limited information about their environment (see [54] and Fig. 2). In contrast, in systems with positive expectations feedback, such as asset markets driven by speculative demand, agents are not able to learn the rational expectations price, but instead they coordinate on successful and self-fulfilling simple trend following strategies causing price fluctuations, excess volatility and persistent deviations from the rational expectations fundamental price [60]. These results generalize the initial findings of [43] that aggregates do not become "well behaved" if there is interdependence in agents' preferences or choices. A simple complexity model thus fits the experimental data both at the micro level of individual forecasting heuristics and the macro level of aggregate price data. Many financial market and macro systems exhibit positive feedback, and a challenge for FuturICT is to study heterogeneous expectations in more realistic complex markets and large web-based experiments.

More and more attention is being paid to situations in which cooperative behaviour evolves in situations where game theory suggests that the solution would be for people to behave in an individualistic way. See for example [24]. One line of reasoning which will be incorporated into FuturICT models is that of "team reasoning" as introduced in Bacharach [13]. This suggests that people involved in a collective venture 

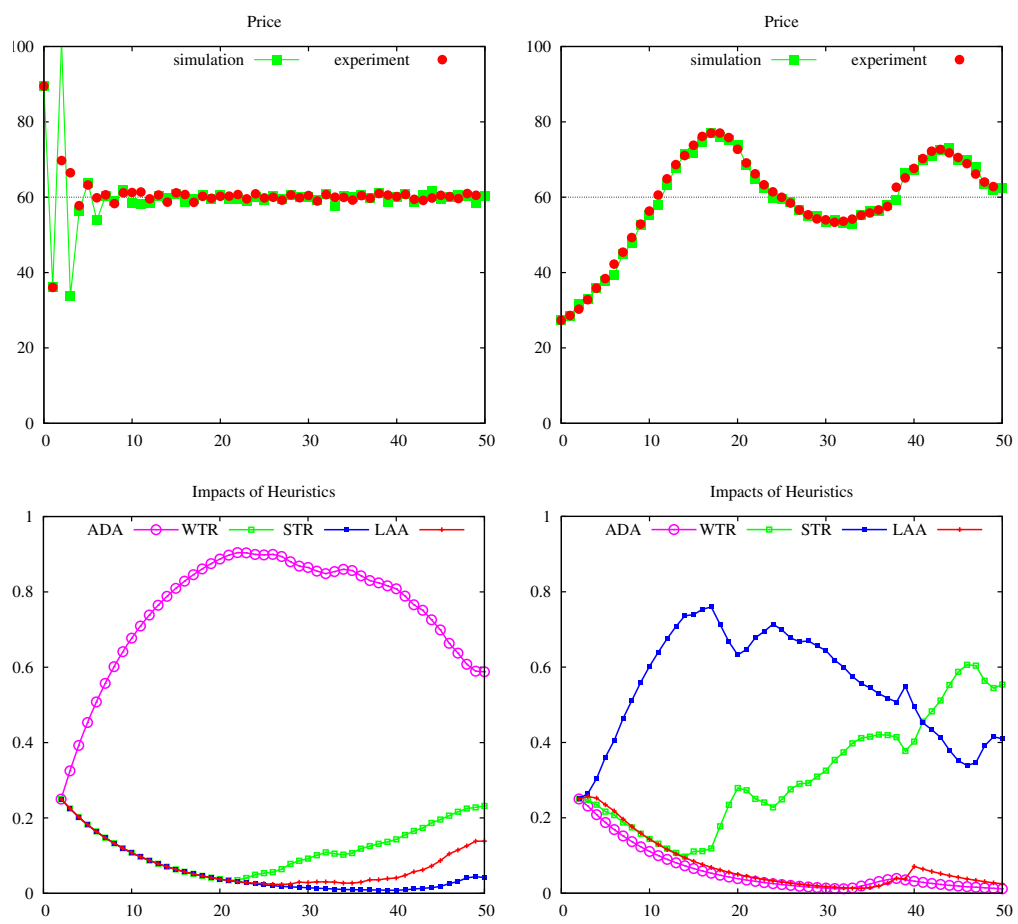

Fig. 2. Laboratory experiments with negative expectations feedback (left panels) and positive expectations feedback (right panels) markets. Realized prices in experiments (top panels, red dots) and simulated prices (top panels, green squares) and corresponding evolution of fractions of 4 strategies in heuristics switching model (bottom panels). Negative feedback markets quickly converge to fundamental equilibrium, with adaptive expectations dominating the market (bottom left panel, purple curve). Positive feedback markets persistently oscillate, due to good performance and amplification by trend following strategies (bottom right panel, blue and green curves).

may redefine their utility to take account of the welfare of the group. Laboratory experiments point out the importance of networks in the emergence of cooperation $[50,98]$. Cooperation and coordination are, highly important features of modern societies and economies and the way in which such cooperation emerges and can be encouraged should be a central theme for FuturICT.

The importance of social learning, of agents altering their behaviour directly as a result of the behaviour of others, is shown by the tournament reported in [89]. A very simple strategy based upon copying proved the most successful, a result not anticipated by the experts who designed the tournament: 'This outcome was not anticipated by the tournament organisers, nor by the committee of experts established to oversee the tournament, nor ... by most of the tournament entrants.'

FuturICT will investigate a wide range of behavioural rules of agents based on different types of social learning, individual learning, reinforcement learning, heterogeneous expectations models and examine which are more capable of explaining the key emergent macro-economic properties of the system than others. In addition to learning models based on principles more familiar to economists, we will draw on models of social learning behaviour from other social sciences such as anthropology and cultural evolution, to build an empirically grounded theory of learning and adaptive behaviour for complex socio-economic systems (for example $[18,19,24,26,51,56,90]$ ). 


\subsection{Innovative policy and market regulation}

A key factor driving the current economic crisis was the excessive use of leverage, i.e. too much borrowing without proper collateral. John Geanakoplos [46] has documented and analyzed the leverage cycle, in which leverage increases due to competition during times of financial stability. The excessive growth of leverage eventually leads to financial instability and triggers a crash; once the financial system stabilizes, the cycle repeats itself. The agent-based simulation of the leverage cycle by Thurner et al. [97] demonstrates this cycle explicitly, and shows how leverage can drive clustered volatility and heavy tails in financial time series. Margin calls, which are made to limit risk and make good sense from the myopic perspective of individual banks, can drive systemic risk when too many banks act in unison. This provides an example of how financial innovations, which were in Lord Turner language mistakenly considered to be "axiomatically beneficial", may be destabilizing in a complex system with boundedly rational interacting agents (Brock, Hommes and Wagener, [25]).

What level of leverage is optimal? Basel III sets leverage levels based on rules of thumb and intuition. The toolkit of FuturICT can potentially make the regulation of leverage much more scientific. In a world of complex inter-locking relationships and contracts, leverage is difficult to even calculate. The proper level for leverage depends on network relationships such as interbank lending (e.g. [48,49]), which can provide security in normal times but may amplify the extent of a crash in bad times. Bank holding companies are highly complex institutions that often have thousands of independent entities - without understanding the network of ownership and control (see e.g. [102]), one cannot properly measure leverage; this is essential to understand what will happen when any given institution is driven bankrupt. The data and network view of FuturICT will make such relationships clearer, and provide a framework for making sound regulatory decisions.

\subsection{Agent-based models as econometric and policy tools}

As we have already mentioned, up until now agent-based models in economics have mainly been qualitative conceptual models. A project to build an ABM for housing markets in the Washington DC area provides a proof-of-principle that it is possible to go beyond this to build a model that is carefully calibrated to real data. Some preliminary results are given in [47], and the results of a typical simulation are shown in Fig. 3.

This model can be used to make predictions about the housing market conditioned on factors such as interest rates, loan policy, immigration, or unemployment, or it can be used to investigate changes in policy, such as interest rates or lending practices.

In this model agents are households who buy and sell houses. Each house is randomly assigned a quality factor based on the distribution of sale prices of real houses, and the assumption is made that quality remains constant and buyers prefer houses of higher quality. Every month a fraction of households decide to move and put their houses up for sale, or attempt to buy a house, e.g. because they decide it is a better alternative than renting. Sellers drop their prices at regular intervals until they find a buyer or remove their house from the market.

The thing that makes this model unique is that most of the characteristics of the households, such as income, employment, frequency of moving, etc. are calibrated to exogenous data. Income, for example, is matched to yearly income distributions from tax returns (which also provide valuable information about the frequency with which 

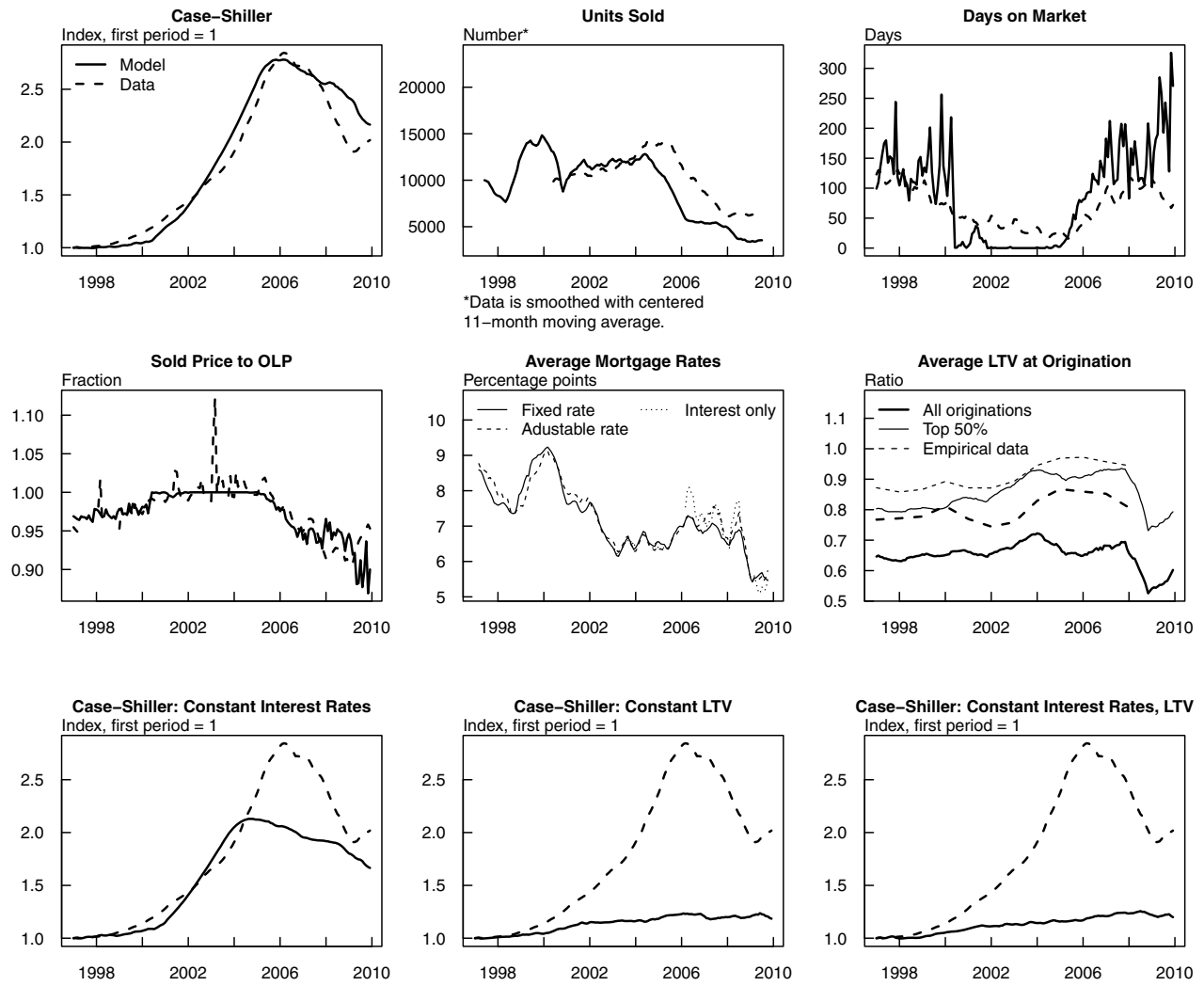

Fig. 3. A comparison of an agent-based simulation of the housing market in the Washington D.C. metropolitan area (solid lines) to real data (dashed lines).

householders move). Census data is used to understand migration and wealth, data on individual mortgages is used to track loan policy, and data from real estate records is used to calibrate the strategies sellers use to adjust their prices.

An example showing a typical run of the model is shown in Figure 3. The first six panels compare six different outputs of the model to the data for the period of the simulation from 1997-2010. Many properties of the model do a good job of matching the data, such as the housing price index, units sold, or days on market. The authors then investigate counter-factual scenarios to assign causality by simulating how the market would have behaved differently had exogenous factors changed. For example, in the lower left panel we see that if interest rates had been held constant there would have still been a bubble, but it would have been much smaller. The lower middle panel shows what would have happened if leverage for buying houses, as measured by the Loan-To-Value ratio (LTV), had remained constant. In this case the bubble disappears entirely. Indeed the scenario where both interest rates and LTV are held constant (lower right) is very similar to the one in which only LTV is held constant. Thus, this model suggests that the dominant cause of the bubble was the extremely liberal lending policies that prevailed during the housing market. Such results would be difficult to achieve with other more traditional methods. This project is still in its early stages and the results are still evolving as the model is improved, but the results so far suggest the potential power of this method. 


\section{Expected paradigm shifts}

A success of FuturICT would constitute a major paradigm shift within the field of economics along at least three dimensions:

1. A new scientific paradigm of a complexity-network approach to economics, emphasizing the idea that the economy is a large but noisy system of interacting agents who are themselves noisy. What is interesting in such systems is not their efficiency, but their capacity to coordinate;

2. The economic discipline needs to become an empirically falsifiable science, both at the individual and at the aggregate level; see e.g. the experiments discussed in 3.4

3. A paradigm shift in economic policy, with the development of a "flight simulator" with advanced ICT tools for policy makers to gain experience in pro-active management of crises in a realistic environment;

4. An analysis of the increased speed of communication on economic activity and firms' growth.

As already discussed, up until now the main methods for macro economic analysis and forecasting have been econometric and DSGE models. A success in this project would introduce a third category of model into the standard toolkit. This would be more than just a technical innovation: It would be a revolution in the way that economics is done, and entirely different way of thinking about the economy.

In the FuturICT view, economics should become an empirically falsifiable science again, both at the micro and at the macro level. "As if" models at the aggregate level are insufficient. Instead, the focus will be on interacting agent-models, calibrated to individual and firm specific data and matching the emerging aggregate properties, and thus matching both micro and macro data. Simple laboratory macro experiments, such as those described in subsection 3.3, show that matching micro and macro behaviour simultaneously is possible. FuturICT will develop methods and tools to match large individual data sets to individual behavior and at the same time match aggregate behaviour of complex socio-economic systems.

In a complex economy, such as that which would be depicted by the models developed in FuturICT, since the consequences of individual choices depend on what all the others are simultaneously doing, people take actions in an environment characterized by radical or endogenous uncertainty. The aggregate outcomes emerging from their continuous and asynchronous localized interactions are almost incomprehensible at an individual level and risk analysis has to be systemic, not individual. In spite of this, modern market economies display a reasonably coordinated state of affairs most of the time. For example they stay within a few percentage points of full-employment, and do not exhibit persistent pathological shortages or surpluses of goods. In other terms, the macroeconomy is characterized both by a substantial resilience and a deep fragility.

This opens the way for some fundamental theoretical and policy questions that FuturICT will address, regarding how built-in feedback mechanisms operate in a complex economy, and how government interventions should both anticipate and react to them to prevent future crises. As Bernanke said "I just think it is not realistic to think that human beings can fully anticipate all possible interactions and complex developments. The best approach for dealing with this uncertainty is to make sure that the system is fundamentally resilient and that we have as many fail-safes and back-up arrangements as possible"

(Interview with the IHT May 17th 2010)

In the remaining part of this section we discuss three of the important questions that arise. 
In the scenario proposed by FuturICT, economic policy prescriptions have fundamentally novel aspects. They stabilize economic system by managing a complex system with heterogeneous agents who interact through networks. It evokes a passage similar to that one from chemotherapy to targeted medicine, with individualized treatment. Two cases: i) network of networks, and ii) immunization strategy or circuit breakers. Some statistical physicists have recently proposed the concept of networks of networks $[29,72]$ where they develop a framework for understanding the robustness of interacting networks subject to cascading failures from one network to another and vice versa. The FOC project linked to the FuturICT proposal has as its aim to study the relationship between the structure of these networks and their propensity to implode (see [16] and [17]). As they point out, it is not enough to look at any of the single nodes in the network. The case of Bear Stearns is an example of a default which occurred even though there was a capital cushion well above what is required to meet supervisory standards calculated using the Basel II standard (Cox, 2008).

To come back to the basic message of FuturICT, regulators have to face the fact that, in many situations, actions ensuring the soundness of one institution (e.g., solvency, liquidity capacity, etc.) may not be consistent with ensuring the soundness of another (Crockett, 2000). On the contrary they may even decrease the stability of the system as a whole. Indeed, local shocks can have systemic repercussions and the requirement to have sounder individuals can have the counter-intuitive effect to make the entire system more fragile. It is interesting to note these issues are very common in the field of complex systems, where the network of agent interactions at the micro level results in the emergence of new behaviour that must be tackled with new global strategies. To quote FOC, "Such an integrated and network-oriented approach invoked by regulators does not exist at the moment. This project aims at developing new indicators that are genuinely constructed with a systemic risk approach starting from microscopic data and, in particular, taking into account the network of mutual exposures among institutions".

Some progress has been made towards obtaining analytical results for the fragility of a network. Indeed under some simplifying assumptions, exact analytical solutions have been obtained for the critical fraction of nodes that, when removed, will lead to a failure cascade and to a complete fragmentation into interdependent networks. They notice that a broader degree distribution increases the vulnerability of interdependent networks to random failure, which is opposite to how a single network behaves. We plan to use the concept of networks of networks in the investigation of the interbank market and of the credit network. In fact there is a network interaction among banks and a network interaction among firms and the credit network among banks and firms links the two networks.

Recent papers have shown that connectivity might favor disease spreading, with domino effects and bankruptcy cascades (reference in Sect. 3.3). FuturICT may envisage how to set some circuit breakers which are activated when, e.g., the average leverage of the actors in a network reaches some critical threshold (two FP7 European projects, FOC and CRISIS, deal with that issue). In a sense, the problem is that of finding the best strategy to immunize a population of agents with a minimal welfare loss. It has been accepted that targeted strategies on most central nodes are most efficient for networks. FuturICT will develop a graph-partitioning strategy, which requires a minimal wealth injection into the system, by isolating its most fragile parts.

\section{Expected impact}

The current economic crisis has reminded us just how important the economy is, and made us acutely aware of our current lack of understanding and our inability 
to manage it. The ability to avert such crises, or to at least lessen their impact and manage them better when they occur, will be enormously valuable. On other levels this project will also have a major impact on science itself, as well as on technology and competitiveness.

\subsection{Impact on science}

As already mentioned, the impact of this project on the field of economics would be enormous. Central bankers are actively seeking tools that would give them a better understanding of the nature of the crises with which they have to deal and the effectiveness of what they are doing in the short and long run. Many economics departments throughout the world have focused considerable resources on providing better tools for central bankers. Regulatory policy analysis is one of the most important practical application of economics, and even small improvements can have big effects. Complex systems analysis and agent-based modelling are so different from the standard approach that a practical success in this domain could trigger a sea-change in the way economics is done.

At present economics stands out as the branch of science where the study of complex systems has had the least impact. Yet, it is clear that periodic endogenous crises are an intrinsic feature of modern economies (see Reinhart and Rogoff's "This time is different" [88]). It is at best on the periphery. A success here could bring economists strongly into the center of the complex systems community.

As should be evident just from the data sets that we envision collecting, the approach that we are taking is highly transdisciplinary. Demonstrating the practical value of transdisciplinary approaches would also have a major impact.

Lastly in this connection, we will make the data we collect available (within legal constraints) to anyone who wishes to work on it. This should be a significant advantage for those who need more complete socio-economic data and represents one of the major advantages of this project for the community at large.

\subsection{Impact on technology and competitiveness}

We envision using state of the art software and hardware to achieve our goals. One of these goals is to develop standard libraries of software tools for agent-based modelling. This could drive software capable of both rapid prototyping and rapid execution.

As it currently stands the United States completely dominates the field of economics. The US has given almost no support to applications of complex systems in economics, in particular agent-based modelling. A success in this area could turn Europe into the leader of the field.

Science depends on funding, and science funding depends on the economy. As argued below, even a minor success in improving our ability to manage the economy is worth an enormous amount, which ultimately impacts science research budgets in every field.

\subsection{Impact on society}

The current crisis has already cost the world an enormous amount, and may yet cost a lot more. Trillions of euros were lost, unemployment soared, and the European Union came under severe stress. The stakes are very high - if this project could mitigate even one percent of the losses, this translates into tens of billions of euros, which would be an ample return on the investment in a flagship project. 
We sometimes forget that almost everything depends on the economy. Economic performance translates directly into human suffering. Poor economic performance means high unemployment, and it also means less money for social services, and lower budgets for the arts and sciences. It is no coincidence that Da Vinci and Michelangelo's coincided with the domination of Florence by the Medici (who directly supported their work).

Finally, a FuturICT Flagship would be a way to assure citizens that the stability and improvement of socio-economic system is one of the main worries of governments, worthy of their attention and one of the main scientific challenges to be addressed in the first big science project in the socio-economic sciences.

The publication of this work was partially supported by the European Union's Seventh Framework Programme (FP7/2007-2013) under grant agreement No. 284709, a Coordination and Support Action in the Information and Communication Technologies activity area ('FuturICT' FET Flagship Pilot Project). Doyne Farmer, Mauro Gallegati and Cars Hommes also acknowledge financial support from the EU-7th framework collaborative project "Complexity Research Initiative for Systemic InstabilitieS (CRISIS)", grant No. 288501. Cars Hommes acknowledges financial support from the Netherlands Organization for Scientific Research (NWO), project "Understanding Financial Instability through Complex Systems". None of the above are responsible for errors in this paper.

\section{References}

1. H.N. Agiza, G.I. Bischi, M. Kopel, Math. Comp. Simul. 51, 63 (1999)

2. G.A. Akerlof, Quarterly J. Econom. 84, 488 (1970)

3. G.A. Akerlof, R.J. Shiller, Animal Spirits: How Human Psychology Drives the Economy, and Why It Matters for Global Capitalism (Princeton University Press, Princeton, 2009)

4. K. Anand, A. Kirman, M. Marsili, Eur. J. Finance 0, 1 (2011)

5. P.W. Anderson, K.J. Arrow, D. Pines (eds.), The Economy as an Evolving Complex System (Addison-Wesley, Redwood City, 1988)

6. K. Arrow, edited by D. Colander, R.P.F. Holt, Barkley J. Rosser, The Changing Face of Economics. Conversations with Cutting Edge Economists, (The University of Michigan Press, Ann Arbor, 2004), p. 291

7. K.J. Arrow, G. Debreu, Econometrica 22, 265 (1954)

8. W.B. Arthur, Amer. Econom. Rev. 84, 406 (1994)

9. W.B. Arthur, J.H. Holland, B. LeBaron, R. Palmer, P. Tayler, in The Economy as an Evolving Complex System II, edited by W.B. Arthur, S.N. Durlauf, D.H. Lane (Addison-Wesley, Redwood City, 1997), p. 15

10. W. Brian Arthur, N. Durlauf, Steven, A. Lane, David (eds.), The Economy as an Evolving Complex system II. SFI Studies in the Complexity of Science, Perseus Books Group (1997)

11. W.B. Arthur, Increasing Returns and Path Dependence in the Economy (University of Michigan Press, Ann Arbor, 1994)

12. P. Auerswald, S. Kauffman, J. Lobo, K. Shell, J. Econom. Dyn. Control 24, 389 (2000)

13. M. Bacharach, Beyond Individual Choice: Teams and Frames in Game Theory, edited by N. Gold, R. Sugden (Princeton University Press, Princeton, 2006)

14. N. Barberis, R.H. Thaler, in Handbook of the Economics of Finance, edited by G.M. Constantinides, M. Harris, R. Stultz (North-Holland, Handbooks in Economics Series, Amsterdam, 2003)

15. S. Battiston, D. Delli Gatti, M. Gallegati, B.C.N. Greenwald, J.E. Stiglitz, J. Econom. Dyn. Control 31 (2007)

16. S. Battiston, D. Delli-Gatti, M. Gallegati, B.C. Greenwald, J.E. Stiglitz, J. Financ. Stab. forthcoming (2012) 
17. S. Battiston, D. Delli-Gatti, M. Gallegati, B.C. Greenwald, J.E. Stiglitz, J. Econom. Dyn. Control, forthcoming (2012)

18. R.A. Bentley, M. O'Brien, P. Ormerod, Mind and Society (in press) (2011)

19. R.A. Bentley, P. Ormerod, M. Batty, Behav. Ecol. Sociobiol. 65, 537 (2011)

20. O.J. Blanchard, Department of Economics Working Paper 08-17, MIT, 2008

21. C.J. Bliss, Capital Theory and the Distribution of Income (North-Holland Publishing Company, Amsterdam, 1975)

22. M. Boss, H. Elsinger, M. Summer, S. Thurner, Quantitative Finance 4, 677 (2004)

23. M. Boss, M. Summer, S. Thurner, Technical report (2004)

24. R. Boyd, H. Gintis, S. Bowles, Science 328, 617 (2010)

25. W. Brock, C. Hommes, F. Wagener, J. Econom. Dyn. Control 33, 1912 (2009)

26. W.A. Brock, S. Durlauf, Rev. Econom. Stud. 68, 235 (2001)

27. W.A. Brock, C.H. Hommes, Econometrica 65, 1059 (1997)

28. William A. Brock, Cars H. Hommes, J. Econom. Dyn. Control 22, 1235 (1998)

29. S.V. Buldyrev, R. Parshani, G. Paul, H.E. Stanley, S. Havlin, Nature 464 (2010)

30. C.F. Camerer, Behavioral Game Theory: Experiments in Strategic Interaction (Princeton University Press, Princeton, 2003)

31. V.M. Carvalho, Technical report, CREI/UPF, 2010

32. S. Cincotti, M. Raberto, A. Teglio, Economics: The Open-Access, Open-Assessment E-Journal, 4 (2010)

33. S. Cincotti, D. Sornette, P. Trelaeven, S. Battiston, G. Caldarelli, C.H. Hommes, A. Kirman, Eur. Phys. J. Special Topics 214, 361 (2012)

34. M.P. Clements, D.F. Hendry, Economic forecasting in a changing world

35. D. Colander, H. Follmer, A. Haas, M.D. Goldberg, K. Juselius, A. Kirman, T. Lux, B. Sloth, Economics Discussion Paper 09-03, Univ. of Copenhagen Dept. (2009)

36. H. Dawid, S. Gemkow, P. Harting, S. van der Hoog, M. Neugart, Working paper, University of Bielefeld (2011)

37. G. Debreu, J. Math. Econom. 1, 15 (1974)

38. D. Delli-Gatti, E. Gaffeo, M. Gallegati, G. Giulioni, A. Pallestrini, Emergent Macroeconomics. An Agent-based Approach to Business Fluctuations (Springer Verlag, Milan, 2008)

39. George W. Evans, S Honkapohja, Learning and Expectations in Macroeconomics (Princeton University Press, 2001)

40. J.D. Farmer, Ind. Corporate Change 11, 895 (2002)

41. J.D. Farmer, D. Foley, Nature 460, 685 (2009)

42. J.D. Farmer, J. Geanakoplos, Complexity 14, 11 (2009)

43. H. Follmer, J. Math. Econom. 1, 51 (1974)

44. A. Fostel, J. Geanakoplos, Amer. Econom. Rev. 98, 1211 (2008)

45. P. Gai and S. Kapadia, Technical Report 383, Bank of England (2010)

46. J. Geanakoplos, Technical Report 1715, Cowles Foundation Discussion Paper (2009)

47. J. Geanakoplos, R. Axtell, D. Farmer, P. Howitt, B. Conlee, J. Goldstein, M. Hendrey, N. Palmer, C-Y. Yang, Amer. Econom. Rev. forthcoming (2012)

48. C.P. Georg, Basel iii and systemic risk regulation - what way forward? Working Paper Series 2, 17-2011, Global Financial Markets (2011)

49. C.P. Georg, Discussion Paper Series 2, 12/2011, Deutsche Bundesbank (2011)

50. J. Grujic, C. Fosco, L. Araujo, J.A. Cuesta, A. Sanchez, PloS ONE 5, e13749 (2010)

51. M.W. Hahn, R.A. Bentley, Proc. Roy. Soc. B 270, S1 (2003)

52. A. Haldane, Rethinking the financial network (2009)

53. A.G. Haldane, R.M. May, Nature 469, 351 (2011)

54. P. Heemeijer, C.H. Hommes, J. Sonnemans, J. Tuinstra, J. Econom. Dyn. Control 33, 1052 (2009)

55. D. Helbing, S. Balietti, Sci. Cult. 76, 399 (2010)

56. J. Henrich, in Innovation in cultural systems: contributions from evolutionary anthropology, edited by M.J. O'Brien, S.J. Shennan (MIT Press, Cambridge, 2010), p. 99

57. C.A. Hidalgo, R. Hausmann, Proc. Nat. Acad. Sci. 106, 10570 (2009) 
58. C.A. Hidalgo, B. Klinger, A.L. Barabasi, R. Hausmann, Science 27, 482 (2007)

59. C.H. Hommes, in Handbook of Computational Economics Vol. 2: Agent-Based Computational Economics, edited by K.L. Judd, L. Tesfatsion (Elsevier/North-Holland, Handbooks in Economics Series, 2006)

60. C.H. Hommes, J. Econom. Dyn. Control 35, 1 (2011)

61. C.H. Hommes, Behavioral rationality and heterogeneous expectations in complex economic systems (Cambridge University Press, 2013)

62. G. Iori, G. De Masi, O. Precup, G. Gabbi, G. Caldarelli, J. Econom. Dyn. Control 32, 259 (2008)

63. G. Iori, S. Jafarey, Physica A 299, 205 (2001)

64. G. Iori, S. Jafarey, F. Padilla, J. Econom. Behav. Organization 61, 525 (2006)

65. D. Kahneman, A. Tversky, Econometrica 47, 263 (1979)

66. A. Kirman, in Money and Financial Markets chapter 17, edited by M. Taylor (Blackwell, Cambridge, 1991), p. 354

67. A.P. Kirman, Econom. J. 99, 129 (1989)

68. A.P. Kirman, Quarterly J. Econom. 108, 137 (1993)

69. B. LeBaron, Calibrating an agent-based financial market, Technical report, Brandeis Economics Dept. (2003)

70. B. LeBaron, in Handbook of Computational Economics, vol. 2: Agent-Based Computational Economics K.L. Judd, L. Tesfatsion (Elsevier/North-Holland Handbooks in Economics Series, 2006)

71. B. LeBaron, W.B. Arthur, R. Palmer, J. Econom. Dyn. Control 23, 1487 (1999)

72. E.A. Leicht, R.M. D'Souza, Technical report, http://arxiv.org

73. H.W. Lorenz, Nonlinear Dynamical Equations and Chaotic Economy (Springer, Berlin, 1993)

74. J. Lorenz, S. Battiston, F. Schweitzer, Eur. Phys. J. B 71, 441 (2009)

75. R.E. Lucas, in The econometrics of price determination Conference, edited by O. Eckstein (Board of Governors of the Federal Reserve System and Social Science Research Council, Washington DC, 1972), p. 50

76. R.E. Lucas, E.C. Prescott, Econometrica 39, 659 (1971)

77. T. Lux, in Handbook of Financial Markets: Dynamics and Evolution, edited by T. Hens, K.R. Schenk-Hoppe (Elsevier, 2009)

78. T. Lux, M. Marchesi, Nature 397, 498 (1999)

79. M. Marsili, Technical report, The Abdus Salam International Centre for Theoretical Physics (2009)

80. J. McNerney, J.D. Farmer, S. Rdener, J.E. Trancik, Proc. Nat. Acad. Sci. 108, 9008 (2011)

81. J.V. Neumann, von, Rev. Econom. Stud. 13, 1 (1945)

82. P. Ormerod, Risk Management 12, 83 (2010)

83. P. Ormerod, E. Evans, Technical Report [arXiv 1103.3457] (2011)

84. M. Raberto, S. Cincotti, Physica A 355, 34 (2005)

85. M. Raberto, S. Cincotti, S.M. Focardi, M. Marchesi, Physica A 299, 319 (2001)

86. M. Raberto, A. Teglio, S. Cincotti, Technical Report 2011-31, Economics Discussion Paper (2011)

87. R. Radner, Econometrica 36, 31 (1968)

88. C.M. Reinhart, K.S. Rogoff, This Time is Different: A Panoramic View of Eight Centuries of Financial Crises (Princeton University Press, 2011)

89. L. Rendell, R. Boyd, D. Cownden, M. Enquist, K. Eriksson, M.W. Feldman, L. Fogarty, S. Ghirlanda, T. Lillicrap, K.N. Laland, Science 328, 208 (2010)

90. P.J. Richerson, R. Boyd, J. Henrich, Proc. Nat. Acad. Sci. 107, 8985 (2010)

91. T.J. Sargent, Bounded Rationality in Macroeconomics (Oxford University Press, 1993)

92. H. Simon, Quarterly J. Econom. 69, 99 (1955)

93. Herbert A. Simon, Models of Man: Social and Rational (John Wiley, New York, 1957)

94. H. Sonnenschein, Econometrica 40, 549 (1972)

95. J. Steindl, Random Processes and the Growth of Firms (Griffin, London, 1965) 
96. J. Stiglitz, S. Salop, Rev. Econom. Stud. 44, 493 (1977)

97. S. Thurner, J.D. Farmer, J. Geanakoplos, Leverage causes fat tails and clustered volatility (2009)

98. A. Traulsen, D. Semmann, R.D. Sommerfeld, H-J. Krambeck, M. Milinski, Proc. Nat. Acad. Sci. 107, 2962 (2010)

99. A.M. Turing, Philoso. Trans. Royal Society B 237, 37 (1952)

100. A. Tversky, D. Kahneman, Science 185, 1124 (1974)

101. S. Vitali, S. Battiston, New J. Phys. 13, 063021 (2011)

102. S. Vitali, J.B. Glattfelder, S. Battiston, PLos ONE 6, e25995 (2011)

103. D. Watts, PNAS 99, 5766 (2002)

104. R. Wilkinson, K. Pickett, The Spirit Level: Why Equality is Better for Everyone (Penguin, 2009)

105. M. Woodford, Amer. Econom. J. Macroeconom. 1 (2009) 